\title{
CORELATION BETWEEN DURATION OF CATHETERIZATION AND PAIN INTENSITY IN PATIENTS WITH URETHRA CATHETERIZATION
}

\author{
Komang Agus Jerry Widyanata ${ }^{1}$, Catur Budi Susilo ${ }^{2}$, Cristin Wiyani ${ }^{3}$ \\ ${ }^{1}$ Akademi Keperawatan Kesdam IX/Udayana \\ ${ }^{2}$ Health Polytechnic Yogyakarta \\ ${ }^{3}$ Respati Yogyakarta University \\ Korespondensi : jerrywidyanata@yahoo.com
}

\begin{abstract}
Background: Urinary catheterization is a medical action that is often carried out for diagnostic and therapeutic purposes. One side effect of catheter placement is pain. Pain felt during catheter placement due to urethral trauma. Pain can be affected by the length of time the catheter is attached. The results of a preliminary study of 5 different patients who were attached to a catheter at different times had different pain intensities. Objective: To find out the relationship between the length of time the catheter is attached to the pain intensity of a patient with a urethral catheter. Method: This study is a non-experimental study with a cross sectional approach. The sampling technique used was Purposive Sampling and the sample size was 38 people. Data collection tools use observation sheets and numeric rating scale (NRS) to assess pain intensity. Bivariate analysis using Pearson Product Moment correlation analysis.

Results: The length of time the catheter is installed is at most two days and one day which are $21.1 \%$ and $18.4 \%$, respectively. The pain intensity of patients with urethral catheters in the lightest category is $42.1 \%$ while the moderate and heavy categories are the same in the amount of $26.3 \%$. The results of bivariate analysis obtained the value of the correlation coefficient $(\rho)$ of -0.914 with $p$ value $0,000(p<0.05)$. Conclusion: There is a significant negative relationship between the difference in catheter-attached time and the pain intensity of a patient with a urethral catheter where the longer the catheter is attached, the less pain is felt.
\end{abstract}

Keywords: Urinary catheterization, pain intensity, duration of catheterization 


\begin{abstract}
ABSTRAK
Latar Belakang : Kateterisasi urin merupakan tindakan medis yang sering dilakukan, baik untuk kepentingan diagnostik maupun terapetik. Salah satu efek samping dari pemasangan kateter itu sendiri adalah nyeri. Nyeri yang dirasakan saat pemasangan kateter karena terjadi trauma uretra. Rasa nyeri yang dirasakan dapat dipengaruhi oleh lama waktu terpasang kateter itu sendiri. Hasil studi pendahuluan kepada 5 pasien berbeda yang terpasang kateter dengan waktu yang berbeda memiliki intensitas nyeri yang berbeda. Tujuan: Mengetahui hubungan antara lama waktu terpasang kateter dengan intensitas nyeri pasien yang terpasang kateter uretra. Metode: Penelitian ini merupakan penelitian non eksperimen dengan pendekatan cross sectional. Teknik sampling yang digunakan adalah Purposive Sampling dengan jumlah sampel 38 orang. Alat pengumpulan data menggunakan lembar observasi dan numeric rating scale (NRS) untuk menilai intensitas nyeri. Analisis bivariat menggunakan analisis korelasi Pearson Product Moment.
\end{abstract}

Hasil: Lama waktu terpasang kateter paling banyak selama dua hari dan satu hari yang masing-masing sebesar $21,1 \%$ dan $18,4 \%$. Intensitas nyeri pasien yang terpasang kateter uretra paling banyak dalam kategori ringan sebesar $42,1 \%$ sedangkan kategori sedang dan berat dalam jumlah yang sama sebesar $26,3 \%$. Hasil analisis bivariat diperoleh nilai koefisien korelasi $(\rho)$ sebesar -0.914 dengan $p$ value $0,000(p<0,05)$.

Kesimpulan: Ada hubungan negatif yang signifikan antara perbedaan waktu terpasang kateter dengan intensitas nyeri pasien yang terpasang kateter uretra dimana semakin lama waktu terpasang kateter maka semakin berkurang nyeri yang dirasakan.

Kata Kunci: Kateterisasi urin, intensitas nyeri, lama waktu terpasang kateter

\title{
Pendahuluan
}

Pemasangan kateter harus sesuai dengan indikasi, dengan prosedur tertentu dan pertimbangan berapa lama dipertahankan karena mempunyai potensi menimbulkan komplikasi baik lokal maupun sistemik. Efek samping dan komplikasi yang mungkin timbul diantaranya adalah rasa tidak nyaman sampai nyeri, terjadi trauma uretra dengan akibat lanjut terjadi penyempitan yang disebut striktur, terjadinya batu, infeksi saluran kemih bahkan dapat terjadi sepsis. Kateter di dalam kandung kemih merupakan benda asing sehingga keberadaannya menimbulkan reaksi dari kandung kemih (Sihono, 2007).

Suatu penelitian prospektif tentang nyeri yang disebabkan oleh karena prosedur medis terhadap pasien-pasien di unit gawat darurat dilakukan oleh Singer, pada tahun 1999 di Rumah Sakit Stony Brook, New York. Dari penelitian tersebut didapat derajat 
nyeri pada kateterisasi uretra berada pada urutan keempat terberat setelah pemasangan pipa lambung, drainase abses dan reposisi patah tulang (Singer, 1999).

Studi pendahuluan yang peneliti lakukan di tiga bangsal yaitu Bangsal Flamboyan, Cempaka, dan Bakung RSUD Panembahan Senopati, mendapatkan data rata-rata pasien yang terpasang kateter uretra selama tiga bulan terkhir di Flamboyan terdapat 28 pasien, di Cempaka 25 pasien, dan di Bakung sebanyak 29 pasien per bulannya. Pergantian kateter untuk pasien yang terpasang kateter menetap dilakukan setiap satu minggu sekali. Setelah menanyakan langsung kepada 5 pasien berbeda yang terpasang kateter dengan waktu yang berbeda, masing-masing selama 1, 2, 4, 5 dan 6 hari memiliki intensitas nyeri yang berbeda, dimana pasien yang baru terpasang kateter selama 1 hari mengatakan lebih nyeri dibandingkan dengan pasien lain yang terpasang kateter lebih dari 1 hari. Begitu juga sebaliknya pasien yang sudah terpasang kateter selama 6 hari merasakan intensitas nyeri yang lebih ringan dibandingkan dengan pasien lain yang terpasang kateter selama kurun waktu kurang dari 6 hari. Selain itu, hasil wawancara dengan perawat setempat mengatakan bahwa respon pasien yang terpasang kateter tampak menahan kesakitan.

Tujuan dari penelitian ini adalah untuk mengetahui hubungan antara lama waktu terpasang kateter dengan intensitas nyeri pada pasien yang terpasang kateter uretra.

\section{Metode}

Rancangan penelitian ini merupakan penelitian noneksperimen dengan menggunakan pendekatan cross sectional, yaitu data yang menyangkut variabel bebas dan variabel terikat akan dikumpulkan dalam waktu yang bersamaan (Notoadmojo, 2010). Populasi dalam penelitian ini adalah semua pasien yang terpasang kateter uretra di Bangsal Penyakit Dalam RSUD Panembahan Senopati, Bantul, Yogyakarta. Sampel pada penelitian ini sebanyak 38 orang. Tehnik yang digunakan untuk pengambilan sampel adalah Non Probability Sampling dengan Purposive Sampling yaitu tehnik penentuan sampel dengan pertimbangan tertentu sesuai yang dikehendaki peneliti (Saryono, 2011). Pasien dimasukan sebagai responden jika pasien dengan umur 21-51 tahun, dan bersedia menjadi responden baik laki-laki maupun perempuan. Sedangkan 
pasien yang dikeluarkan sebagai responden adalah pasien buta huruf dan mengalami nyeri selain nyeri yang diakibatkan oleh pemasangan kateter.

Instrumen yang digunakan dalam penelitian ini adalah lembar observasi yang berisi penilaian lama waktu terpasang kateter dan numeric rating scale (NRS) untuk menilai skala nyeri. Analisis data yang dilakukan adalah analisa univariat untuk mengetahui presentase dari tiap variabel, baik variabel bebas (lama waktu terpasang kateter) maupun variabel terikat (intensitas nyeri) dan analisa bivariate untuk mengetahui hubungan kedua variable. Pada penelitian ini teknik uji statistik yang digunakan dalam menganalisa tentang hubungan perbedaan waktu terpasang kateter terhadap intensitas nyeri adalah korelasi Pearson Product Moment. Korelasi Pearson Product Moment digunakan untuk menguji hubungan antara dua variabel dengan skala data interval atau rasio dengan interval atau rasio (Riwidikdo, 2009).

\section{HASIL}

1. Karakteristik Responden

Tabel 1 Distribusi Frekuensi Karakteristik Responden Berdasarkan Usia, Jenis Kelamin, dan Penyakit penyerta

\begin{tabular}{lcc}
\hline Karakteristik Responden & Frekuensi & Persentase (\%) \\
\hline Umur & 13 & \\
$30-40$ tahun & 24 & 34,2 \\
$41-50$ tahun & 1 & 63,2 \\
$51-60$ tahun & $\mathbf{3 8}$ & 2,6 \\
\hline Jumlah & & $\mathbf{1 0 0}$ \\
\hline Jenis kelamin & 23 & 60,5 \\
Laki-laki & 15 & 39,5 \\
Perempuan & $\mathbf{3 8}$ & $\mathbf{1 0 0}$ \\
\hline Jumlah & & \\
\hline Penyakit penyerta & 11 & 28.9 \\
Diabetes militus & 10 & 26.3 \\
Gangguan fungsi ginjal & 17 & 44.7 \\
Hipertensi & $\mathbf{3 8}$ & $\mathbf{1 0 0}$ \\
\hline Total & & \\
\hline
\end{tabular}

Sumber : Data primer diolah, 2012. 
Tabel 2 Distribusi Lama Waktu Terpasang Kateter di Ruang Flamboyan, Cempaka, dan Bakung RSUD Panembahan Senopati, Bantul

\begin{tabular}{ccc}
\hline $\begin{array}{c}\text { Lama waktu } \\
\text { terpasang kateter }\end{array}$ & $\mathrm{N}$ & $\%$ \\
\hline Satu hari & 7 & 18,4 \\
Dua hari & 8 & 21,1 \\
Tiga hari & 7 & 18,4 \\
Empat hari & 6 & 15,8 \\
Lima hari & 4 & 10,5 \\
Enam hari & 3 & 7,9 \\
Tujuh hari & 3 & 7,9 \\
\hline Jumlah & 38 & 100 \\
\hline
\end{tabular}

Sumber : Data primer diolah, 2012.

Berdasarkan tabel 2 dapat diketahui bahwa sebagian besar responden mengalami lama waktu terpasang kateter selama dua hari dan satu yang masing-masing sebanyak 8 responden $(21,1 \%)$ dan sebanyak 7 responden $(18,4 \%)$, dan kemudian responden yang mengalami lama waktu terpasang kateter paling sedikit adalah selama enam dan tujuh hari yaitu sebanyak 3 responden (7,9\%). Hal ini menunjukkan bahwa sebagian besar pasien yang terpasang kateter pada saat penelitian dilakukan adalah selama dua hari.

Tabel 3 Distribusi Intensitas Nyeri Pasien Yang Terpasang Kateter Uretra di Bangsal Flamboyan, Cempaka, dan Bakung RSUD Panembahan Senopati, Bantul

\begin{tabular}{ccc}
\hline Intensitas Nyeri & $\mathrm{N}$ & $\%$ \\
\hline Tidak Ada Nyeri & 2 & 5,3 \\
Nyeri Ringan & 16 & 42,1 \\
Nyeri Sedang & 10 & 26,3 \\
Nyeri berat & 10 & 26,3 \\
Nyeri tak tertahankan & 0 & 0,0 \\
\hline Jumlah & 38 & 100 \\
\hline
\end{tabular}

Sumber : Data primer diolah, 2012.

Berdasarkan tabel 3 dapat diketahui bahwa sebagian besar responden merasakan intensitas nyeri dalam kategori ringan yaitu sebanyak 16 responden $(42,1 \%)$, kemudian responden yang merasakan intensitas nyeri dalam kategori nyeri sedang dan berat 
dalam jumlah yang sama masing masing sebanyak 10 responden $(26,3 \%)$, dan intensitas nyeri tak tertahankan terdapat 0 responden $(0,0 \%)$. Hal ini menunjukkan bahwa sebagian besar pasien merasakan intensitas nyeri dalam kategori ringan.

Tabel 4 Distribusi Hubungan Lama Waktu Terpasang Kateter Dengan Intensitas Nyeri Pasien Yang Terpasang Kateter Uretra

\begin{tabular}{|c|c|c|c|c|c|c|c|c|c|c|c|c|}
\hline \multirow{3}{*}{$\begin{array}{l}\text { Lama } \\
\text { waktu }\end{array}$} & \multicolumn{8}{|c|}{ Nyeri } & & & \multirow{3}{*}{$\mathrm{r}$} & \multirow{3}{*}{$P$-value } \\
\hline & \multicolumn{2}{|r|}{ Berat } & \multicolumn{2}{|r|}{ Sedang } & \multicolumn{2}{|r|}{ Ringan } & \multicolumn{2}{|c|}{$\begin{array}{c}\text { Tak ada } \\
\text { nyeri }\end{array}$} & \multicolumn{2}{|r|}{ Total } & & \\
\hline & $\mathrm{f}$ & $\%$ & $f$ & $\%$ & $f$ & $\%$ & $\mathrm{f}$ & $\%$ & $\mathrm{f}$ & $\%$ & & \\
\hline Satu Hari & 7 & 18,4 & 0 & 0,0 & 0 & 0,0 & 0 & 0,0 & 7 & 18,4 & & \\
\hline Dua hari & 3 & 7,8 & 5 & 13,1 & 0 & 0,0 & 0 & 0,0 & 8 & 21,1 & & \\
\hline Tiga hari & 0 & 0,0 & 4 & 10,5 & 3 & 7,8 & 0 & 0,0 & 7 & 18,4 & & \\
\hline $\begin{array}{c}\text { Empat } \\
\text { hari }\end{array}$ & 0 & 0,0 & 0 & 0,0 & 6 & 15,8 & 0 & 0,0 & 6 & 15,8 &,- 914 & 0,000 \\
\hline Lima hari & 0 & 0,0 & 1 & 2,6 & 3 & 7,8 & 0 & 0,0 & 4 & 10,5 & & \\
\hline Enam hari & & 0,0 & 0 & 0,0 & 3 & 7,8 & 0 & 0,0 & 3 & 7,9 & & \\
\hline Tujuh hari & & 0,0 & 0 & 0,0 & 1 & 2,6 & 2 & 5,3 & 3 & 7,9 & & \\
\hline Total & 10 & 26,3 & 10 & 26,3 & 16 & 42,1 & 2 & 5,3 & 38 & 100 & & \\
\hline
\end{tabular}

Sumber : Data primer diolah, 2012.

Berdasarkan Tabel 4 maka dapat dijelaskan tentang ada tidaknya hubungan antara perbedaan waktu terpasang kateter dengan intensitas nyeri pasien yang terpasang kateter uretra para pasien di RSUD Panembahan Senopati, Bantul, dari pengujian diatas diperoleh nilai signifikan pada hubungan antara kedua variabel tersebut sebesar 0,000. Dikarenakan nilai signifikan 0,000 lebih kecil dari nilai signifikan 0,05 atau $(0,000<0,05)$, maka dinyatakan ada hubungan yang signifikan antara perbedaan waktu terpasang kateter dengan intensitas nyeri pasien yang terpasang kateter uretra, sehingga hipotesis yang menyatakan bahwa ada hubungan antara perbedaan waktu terpasang kateter pasien dengan intensitas nyeri pasien yang terpasang kateter uretra di RSUD Panembahan Senopati, Bantul terbukti atau diterima. 


\section{Pembahasan}

\section{Lama Waktu Terpasang Kateter}

Pada penelitian ini ditemukan sebagian besar responden mengalami lama waktu terpasang kateter selama dua hari yaitu sebanyak 8 orang $(21,1 \%)$ dan kemudian responden yang mengalami lama waktu terpasang kateter paling sedikit adalah selama enam dan tujuh hari masing-masing sebanyak 3 orang (7,9\%). Hal ini menunjukkan bahwa sebagian besar pasien yang terpasang kateter pada saat penelitian dalam waktu yang relative singkat. Hal ini dikarenakan oleh indikasi pemasangan kateter uretra yang mebutuhkan waktu yang tidak begitu lama. seperti yang dikemukakan Sihono (2007), yaitu Indikasi pemasangan kateter antara lain, untuk kepentingan diagnostik yaitu pengambilan sample urine pada wanita agar terhindar dari kontaminasi, mengitung residu urine bila dengan cara pemeriksaan lain tidak bisa dilakukan, tindakan diagnostik untuk mengetahui volume residu urine setelah kencing sepuaspuasnya pada pasien yang dicurigai adanya retensi urine dengan syarat pasien masih dapat kencing, kepentingan radiologis untuk pencitraan kandung kemih dan uretra dan akurasi penghitungan produksi urine pada pasien yang sedang dirawat.

\section{Intensitas Nyeri}

Pada penelitian ini intensitas nyeri ringan yaitu sebanya 16 responden $(42,1 \%)$, kemudian responden yang merasakan intensitas nyeri dalam kategori nyeri sedang dan berat dalam jumlah yang sama masing masing sebanyak 10 responden $(26,3 \%)$, dan intensitas nyeri tidak tertahankan terdapat 0 responden $(0,0 \%)$. Hal ini menunjukkan bahwa sebagian besar pasien merasakan intensitas nyeri dalam kategori ringan.. Tidak adanya rasa nyeri tidak tertahankan ini menunjukkan pada pemasangan kateter sudah sesuai dengan prosedur dan pertimbangan perawatan, hal ini sesuai pendapat (Sihono, 2007), yang menyatakan efek samping dan komplikasi yang mungkin timbul diantaranya adalah rasa tidak nyaman sampai nyeri, terjadi trauma uretra dengan akibat lanjut terjadi penyempitan yang disebut striktur, terjadinya batu, infeksi saluran kemih bahkan dapat terjadi sepsis. Kateter di dalam kandung kemih merupakan benda asing sehingga keberadaannya menimbulkan reaksi dari kandung kemih. 
Nyeri adalah pengalaman sensori serta emosi yang tidak menyenangkan dan meningkat akibat adanya kerusakan jaringan yang aktual atau potensial, digambarkan dalam istilah seperti kerusakan (Wilkinson, 2007). Kerusakan jaringan dapat disebabkan oleh adanya benda asing yang masuk ke dalam tubuh, pada penelitian ini benda asing tersebut adalah kateter uretra.

\section{Hubungan Antara lama Waktu Terpasang Kateter Dengan Intensitas Nyeri Pasien Yang Terpasang Kateter uretra}

Berdasarkan pengujian statistik dengan uji Korelasi Product Moment, dinyatakan ada hubungan yang signifikan dan tinggi antara perbedaan waktu terpasang kateter dengan intensitas nyeri pasien yang terpasang kateter uretra, sehingga hipotesis yang menyatakan bahwa ada hubungan antara perbedaan waktu terpasang kateter dan intensitas nyeri pasien yang terpasang kateter uretra terbukti atau diterima. Hubungan antara kedua variabel berbanding terbalik ditandai dengan adanya nilai minus (-) pada nilai korelasi, hal ini memiliki makna bahwa semakin lama terpasang kateter maka semakin rendah intensitas nyeri yang dirasakan oleh pasien yang terpasang kateter uretra.

Rasa nyeri lebih tinggi dirasakan pada awal terpasang kateter dan semakin lama semakin berkurang, hal ini menunjukan bahwa masih perlu diperhatikan protap pemasangan kateter itu sendiri sehingga efek nyeri yang ditimbulkan dapat berkurang. Selain itu dapat juga dipengaruhi oleh proses adaptasi, diamana orang yang terpasang kateter akan berusaha beradaptasi dengan kondisi yang dihadapinya baik secara fisiologis maupun psikologis seperti yang dikemukakan oleh Roy, yang dikutip oleh Nursalam (2003) mekanisme belajar merupakan suatu proses didalam sistem adaptasi (cognator) yang meliputi mempersepsikan suatu informasi, baik dalam bentuk implisit maupun eksplisit. Belajar implisit umumnya bersifat reflektif dan tidak memerlukan kesadaran (focal) sebagaimana terlihat pada gambar. Keadaan ini ditemukan pada perilaku kebiasaan, sensitisasi dan keadaan. 


\section{Simpulan}

Karakteristik nyeri yang dirasakan pasien terpasang kateter uretra masuk kedalam kategori nyeri ringan. Hasil penelitian ini menunjukan bahwa nyeri yang dirasakan pasien akibat terpasang kateter uretra semakin lama semakin mengalami penurunan, dalam kata lain nyeri yang paling berat dirasakan dalam proses dan selama terpasang kateter uretra adalah saat pemasangan kateter itu sendiri. Hal tersebut terjadi karena dalam proses pemasangan kateter terjadi pergesekan yang cukup keras antara selang kateter dengan uretra yang menyebabkan stimulus nyeri. Sedangkan, seiring dengan berjalanya waktu, nyeri yang dirasakan akibat pemasangan kateter uretra semakin berkurang bahkan hilang, hal tersebut disebabkan karena adanya proses adaptasi diamana orang yang terpasang kateter akan berusaha beradaptasi dengan kondisi yang dihadapinya baik secara fisiologis maupun psikologis.

\section{DAFTAR PUSTAKA}

Brunner \& Suddarth. 2000. Buku Ajar Keperawatan Medikal Bedah (Edisi 8). Jakarta: EGC

Notoatmojo, S. 2010. Metodologi Penelitian Kesehatan. Jakarta: Rineka Cipta

Nursalam. 2008. Konsep Dan Penerapan Metodologi Penelitian Ilmu Keperawatan. Jakarta: Salemba Medika

Rowidikdo, Handoko. 2009. Statistik Kesehatan. Yogyakarta: Mitra Cendikia

Saryono. 2011. Metodologi Penelitian Kesehatan. Yogyakarta: Mitra Cendikia

Sihono, Adi. 2007. Hasil Guna Pemberian Tumsulosin (harnal) dan Tolterodin (detrusitol) Untuk Rasa Tidak Nyaman Karena Kateter Uretra Menetap Dengan Parameter Sfmpq Pada Pasien Yang Menjalani Operasi Dengan Anastesi Spinal Di Rs Dr. Sardjito Yogyakarta. Tesis. Universitas Gadjah Mada

Singer, A.J., Richman. P.B.,Kowalska, A., Thode, H.C., 1999. Comparison of Patient and Practitioner Assessments of Pain From Commonly Performed Emergency Department Procedures (Abstract). Ann. Emerg. Med. (Jun):652-638. http.//www.ncbi.nlm.nih.gov/entrez/query.fcgi

Wilkinson, Judith M. 2007. Buku Saku Diagnosa Keperawatan. Jakarta: EGC 